\title{
Insight into biosorption equilibrium, kinetics and thermodynamics of crystal violet onto Ananas comosus (pineapple) leaf powder
}

\author{
Sagnik Chakraborty $\cdot$ Shamik Chowdhury $\cdot$ \\ Papita Das Saha
}

Received: 17 October 2011 / Accepted: 2 February 2012/Published online: 21 February 2012

(C) The Author(s) 2012. This article is published with open access at Springerlink.com

\begin{abstract}
Biosorption performance of pineapple leaf powder (PLP) for removal of crystal violet (CV) from its aqueous solutions was investigated. To this end, the influence of operational parameters such as $\mathrm{pH}$, biosorbent dose, initial dye concentration and temperature were studied employing a batch experimental setup. The biosorption process followed the Langmuir isotherm model with high correlation coefficients $\left(R^{2}>0.99\right)$ at different temperatures. The maximum monolayer biosorption capacity was found to be $78.22 \mathrm{mg} \mathrm{g}^{-1}$ at $293 \mathrm{~K}$. The kinetic data conformed to the pseudo-second-order kinetic model. The activation energy of the system was calculated as $58.96 \mathrm{~kJ} \mathrm{~mol}^{-\mathbf{1}}$, indicating chemisorption nature of the ongoing biosorption process. A thermodynamic study showed spontaneous and exothermic nature of the biosorption process. Owing to its low cost and high dye uptake capacity, PLP has potential for application as biosorbent for removal of $\mathrm{CV}$ from aqueous solutions.
\end{abstract}

Keywords Biosorption - Pineapple leaf powder . Crystal violet $\cdot$ Equilibrium $\cdot$ Kinetics $\cdot$ Thermodynamics

\section{Introduction}

The release of synthetic dye stuffs through the wastewater streams of industries such as textile, leather, rubber, paper, printing, paint, plastic, pigments, food and cosmetics is a serious global concern (Chowdhury et al. 2011a). This is

S. Chakraborty $\cdot$ S. Chowdhury $(\bowtie) \cdot$ P. D. Saha Department of Biotechnology, National Institute of Technology-Durgapur, Mahatma Gandhi Avenue, Durgapur, WB 713209, India

e-mail: chowdhuryshamik@gmail.com mainly because of their negative ecotoxicological effects into the receiving water bodies and bioaccumulation in wildlife (Saha et al. 2010). Therefore, such dye effluent stream requires proper treatment prior to discharge.

In recent years, biosorption has been strongly recommended by researchers worldwide as an efficient and economically sustainable technology for the removal of synthetic dyes from industrial effluents (Farooq et al. 2010; Rafatullah et al. 2010; Demribas 2009; Gupta and Suhas 2009). A number of non-conventional low-cost materials, particularly agricultural waste/by-products such as rice husk, rice bran, wheat bran, orange peel, banana pith, banana peel, plum kernels, apple pomace, wheat straw, sawdust, coir pith, sugarcane bagasse, tea leaves, bamboo dust etc. have been proposed by several workers as effective biosorbents for the removal of dyes from their aqueous solutions (Gupta and Suhas 2009; Chowdhury et al. 2010).

Pineapple (Ananas comosus) is largely cultivated in tropical countries like India, China, Thailand, Indonesia and Taiwan and is consumed worldwide (Chowdhury et al. 2011b). Upon harvest, the leaves and stem cause potential disposal problems since they exist in enormous quantities and have no practical utility. Although direct open burning in fields is a common option for disposal, but this alternative causes serious air pollution. Thus the use of pineapple wastes as biosorbent is an attractive alternative from both economical and environmental point of view. Our previous study demonstrates that pineapple leaves in powdered form could be employed as an effective biosorbent for the removal of Basic Green 4 from aqueous solutions (Chowdhury et al. 2011b). Hence, a further attempt of the feasibility of applying pineapple leaf powder (PLP) for the removal of crystal violet (CV) dye from aqueous solution was explored in the present study. The study includes an evaluation of the effects of various 
operational parameters such as initial dye concentration, biosorbent dose, temperature and $\mathrm{pH}$ on the dye biosorption process employing a batch experimental setup. Biosorption isotherms and kinetics of the sorption process were studied. Also, thermodynamic and activation parameters were calculated in order to estimate the performance and predict the mechanism of the biosorption process.

\section{Experimental}

\section{Biosorbent}

Mature pineapple leaves were collected from the local farmlands in Durgapur, West Bengal, India. The leaves were first thoroughly washed with tap water to remove dust, dirt and any unwanted particles. The leaves were then sun dried and subsequently oven dried at $363 \pm 1 \mathrm{~K}$ for $24 \mathrm{~h}$. The dried leaves were ground to fine powder using a grinder and sieved to a constant size $(100-125 \mu \mathrm{m})$ and used as biosorbent without any pretreatment for $\mathrm{CV}$ biosorption. The characterization of the biosorbent has been previously reported (Chowdhury et al. 2011b).

Dye

Crystal violet (CV) used in this study was of commercial quality (CI 42555, MF: $\mathrm{C}_{25} \mathrm{H}_{30} \mathrm{~N}_{3} \mathrm{Cl}, \mathrm{MW}: 408, \lambda_{\max }$ : $580 \mathrm{~nm}$ ) and was used without further purification. Stock solution $\left(1,000 \mathrm{mg} \mathrm{L}^{-1}\right)$ was prepared by dissolving accurately weighed quantity of the dye in double-distilled water. Experimental dye solution of different concentrations was prepared by diluting the stock solution with suitable volume of double-distilled water. The initial solution $\mathrm{pH}$ was adjusted using $0.1 \mathrm{M} \mathrm{HCl}$ and $0.1 \mathrm{M}$ $\mathrm{NaOH}$ solutions.

\section{Batch biosorption experiments}

Batch biosorption experiments were carried out in $250 \mathrm{~mL}$ glass-stopperred, Erlenmeyer flasks with $100 \mathrm{~mL}$ of working volume, with a concentration of $50 \mathrm{mg} \mathrm{L}^{-1}$. A weighed amount $(2 \mathrm{~g})$ of biosorbent was added to the solution. The flasks were agitated at a constant speed of $150 \mathrm{rpm}$ for $3 \mathrm{~h}$ in an incubator shaker (Innova 42, New Brunswick Scientific, Canada) at $303 \pm 1 \mathrm{~K}$. The influence of $\mathrm{pH}$ (3.0-10.0), initial dye concentration (20-100 $\left.\mathrm{mg} \mathrm{L}^{-1}\right)$, biosorbent dose $\left(0.5-5 \mathrm{~g} \mathrm{~L}^{-1}\right)$ and temperature (293-313 K) were evaluated during the present study. Samples were collected from the flasks at predetermined time intervals for analyzing the residual dye concentration in the solution. The residual amount of dye in each flask was investigated using UV/VIS spectrophotometer
(U-2800, Hitachi, Japan). The amount of dye adsorbed per unit PLP (mg dye per g biosorbent) was calculated according to a mass balance on the dye concentration using Eq. (1):

$q_{\mathrm{e}}=\frac{\left(C_{\mathrm{i}}-C_{\mathrm{e}}\right) V}{m}$

where $C_{i}$ is the initial dye concentration $\left(\mathrm{mg} \mathrm{L}^{-1}\right), C_{\mathrm{e}}$ is the equilibrium dye concentration in solution $\left(\mathrm{mg} \mathrm{L}^{-1}\right), V$ is the volume of the solution (L), and $m$ is the mass of the biosorbent $(\mathrm{g})$. The percent removal $(\%)$ of dye was calculated using the following equation:

$\operatorname{Removal}(\%)=\frac{C_{\mathrm{i}}-C_{\mathrm{e}}}{C_{\mathrm{i}}} \times 100$

All the biosorption experiments were performed in triplicate. The results are the average of three independent measurements along with standard deviation $( \pm \mathrm{SD})$ showing $95 \%$ confidence level with a precision in most cases being $\pm 2 \%$. Microsoft Excel program was employed for data processing. Linear regression analyses were used to determine slopes and intercepts of the linear plots and for statistical analyses of the data.

\section{Results and discussion}

\section{Effect of $\mathrm{pH}$}

To investigate the effect of solution $\mathrm{pH}$ on the biosorption of CV by PLP, a series of batch biosorption experiments as described above were carried out over a $\mathrm{pH}$ range of 3-10. The results thus obtained are shown in Fig. 1. The biosorption capacity increased with increase in $\mathrm{pH}$ of the dye

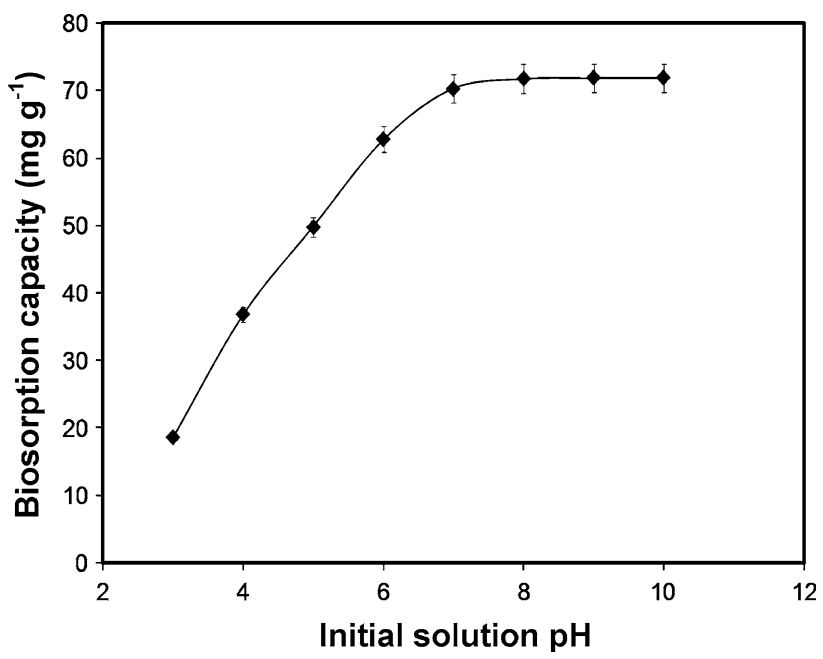

Fig. 1 Effect of $\mathrm{pH}$ on biosorption of $\mathrm{CV}$ by PLP (experimental conditions: initial dye concentration $50 \mathrm{mg} \mathrm{L}^{-1}$, biosorbent dosage $2 \mathrm{~g} / 0.1 \mathrm{~L}$, agitation speed: $150 \mathrm{rpm}$, temperature $303 \mathrm{~K}$, contact time $3 \mathrm{~h})$ 
solution, appreciably up to $\mathrm{pH}$ 8.0. With further increase in $\mathrm{pH}$, no significant change in dye binding capacity was observed. Thus, all further experiments were carried out at pH 8.0. A quite similar result was previously reported for biosorption of $\mathrm{CV}$ from aqueous solution by treated ginger waste (Kumar and Ahmad 2011).

The $\mathrm{pH}$ of the aqueous solution affects both the surface charge of the biosorbent material as well as the degree of ionization of the dye molecule (Saha et al. 2010). PLP mainly contains $-\mathrm{OH},-\mathrm{CH},-\mathrm{NH}_{2}$ and $-\mathrm{C}-\mathrm{O}$ functional groups on its surface (Chowdhury et al. 2011b). Protonation of these functional groups at low $\mathrm{pH}$ values renders a net negative charge to the biosorbent surface while deprotonation of the functional groups at high $\mathrm{pH}$ values render it positively charged. The $\mathrm{p} K_{\mathrm{a}}$ of $\mathrm{CV}$ is 0.8 ; it is completely ionized at $\mathrm{pH}$ greater than 0.8 and exists as cationic species (Saha et al. 2012). At low pH values, there exists a strong electronegative repulsion between the positively charged dye ions and the negatively charged biosorbent surface resulting in low dye binding capacity. However, as the $\mathrm{pH}$ of the dye solution increases, a considerable increase in dye binding capacity is observed due to strong electrostatic attraction between negatively charged sites on the biosorbent and the dye cations.

\section{Effect of biosorbent dose}

The influence of biosorbent dose on the $\mathrm{CV}$ biosorption capacity of PLP was investigated in the range of $0.5-5 \mathrm{~g}$. The results obtained are summarized in Fig. 2. The percentage dye removal increases with increase of biosorbent

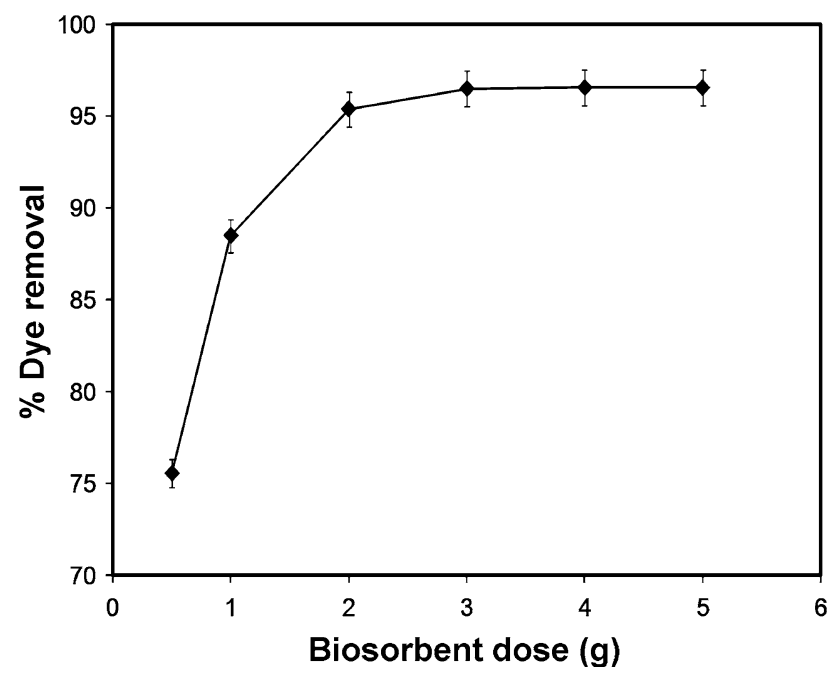

Fig. 2 Effect of biosorbent dose on biosorption of CV by PLP (experimental conditions: initial dye concentration: $50 \mathrm{mg} \mathrm{L}^{-1}$, agitation speed $150 \mathrm{rpm}, \mathrm{pH} 8.0$, temperature $303 \mathrm{~K}$, contact time $3 \mathrm{~h})$ dose from 0.5 to $2 \mathrm{~g}$. It may be explained that increasing the biosorbent dose resulted in increased biosorbent surface area and availability of more binding sites (Saha et al. 2010). However, further increase in biosorbent dose did not significantly change the biosorption yield. This is due to the binding of almost all dye molecules to the biosorbent surface and the establishment of equilibrium between the dye molecules on the biosorbent and in the solution (Saha et al. 2010). These observations are in agreement with those reported previously by Saeed et al. (2010) for biosorption of $\mathrm{CV}$ by grapefruit peels.

\section{Effect of initial dye concentration}

Figure 3 shows the biosorption performance of PLP at different initial concentration of $\mathrm{CV}$ in the range of 20-100 $\mathrm{mg} \mathrm{L}^{-1}$. The adsorption capacity increased from 62.36 to $80.15 \mathrm{mg} \mathrm{g}^{-1}$ with increase in initial dye concentration from 20 to $100 \mathrm{mg} \mathrm{L}^{-1}$. The increase in dye uptake capacity can be attributed to the fact that increasing concentration gradient provides an increasing driving force to overcome all mass transfer resistances of the dye molecules between the aqueous and solid phase, leading to an increased equilibrium uptake capacity until sorbent saturation is achieved (Chowdhury and Das 2011). On the contrary, the biosorption efficiency decreased with increase in initial dye concentration. This is mainly because all sorbents have a limited number of binding sites, which become saturated at a certain concentration (Chowdhury and Das 2011). Similar results have been reported for biosorption of CV by Sagaun sawdust (Khattri and Singh 2011).

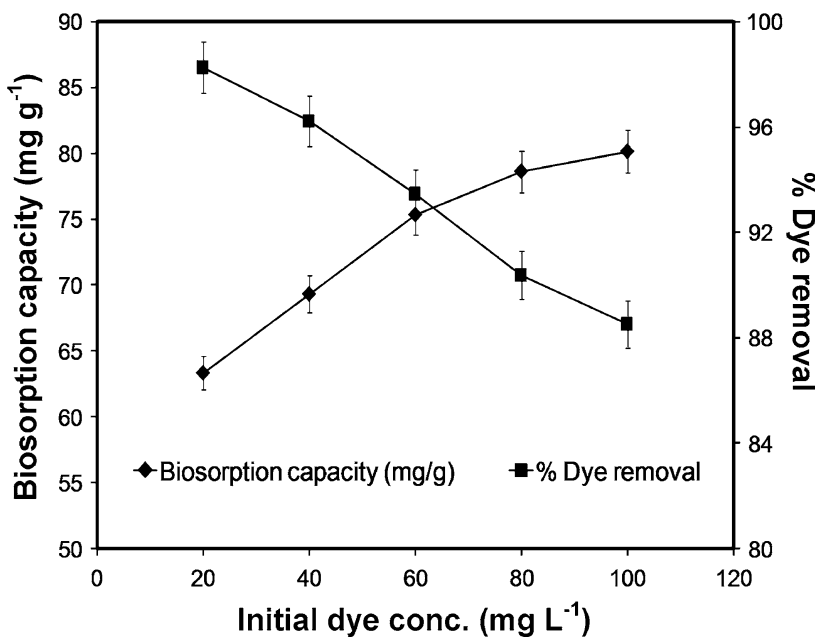

Fig. 3 Effect of initial dye concentration on biosorption of CV by PLP (experimental conditions: biosorbent dosage $2 \mathrm{~g} / 0.1 \mathrm{~L}$, agitation speed $150 \mathrm{rpm}, \mathrm{pH} 8.0$, temperature $303 \mathrm{~K}$, contact time $3 \mathrm{~h}$ ) 


\section{Effect of temperature}

Figure 4 presents the biosorption profile of CV by PLP at different temperatures. The dye removal efficiency decreased with increase in temperature over the range of 293-303 K. Increase in temperature results in weakening of the bonds between the dye molecules and the binding sites of the biosorbent leading to low dye removal efficiency (Chakraborty et al. 2011). Such a trend is indicative of the fact that biosorption of CV by PLP is kinetically controlled by an exothermic process. Similar phenomenon was also observed for biosorption of $\mathrm{CV}$ by $\mathrm{NaOH}$-modified rice husk (Chakraborty et al. 2011).

\section{Biosorption isotherms}

The Langmuir and Freundlich isotherm models were used to describe the equilibrium biosorption data of $\mathrm{CV}$ onto PLP (Chowdhury and Saha 2010).

Langmuir: $\frac{C_{\mathrm{e}}}{q_{\mathrm{e}}}=\frac{C_{\mathrm{e}}}{q_{\mathrm{m}}}+\frac{1}{K_{\mathrm{L}} q_{\mathrm{m}}}$

Freundlich: $\log q_{\mathrm{e}}=\log K_{\mathrm{F}}+\left(\frac{1}{n}\right) \log C_{\mathrm{e}}$

where $q_{\mathrm{e}}\left(\mathrm{mg} \mathrm{g}^{-1}\right)$ and $C_{\mathrm{e}}\left(\mathrm{mg} \mathrm{L}^{-1}\right)$ are the solid phase concentration and the liquid phase concentration of adsorbate at equilibrium, respectively, $q_{\mathrm{m}}\left(\mathrm{mg} \mathrm{g}^{-1}\right)$ is the maximum adsorption capacity, $K_{\mathrm{L}}\left(\mathrm{L} \mathrm{mg}^{-1}\right)$ is the Langmuir adsorption equilibrium constant, $K_{\mathrm{F}} \quad\left(\mathrm{mg} \mathrm{g}^{-1}\right)$ $\left(\mathrm{L} \mathrm{g}^{-1}\right)^{1 / n}$ is the Freundlich constant related to sorption capacity and $n$ is the heterogeneity factor.

The parameters obtained from the Langmuir $\left(C_{\mathrm{e}} / \mathrm{q}_{\mathrm{e}} \mathrm{vs}\right.$. $\left.C_{\mathrm{e}}\right)$ and Freundlich $\left(\log q_{e}\right.$ vs. $\left.\log C_{\mathrm{e}}\right)$ isotherm plots are

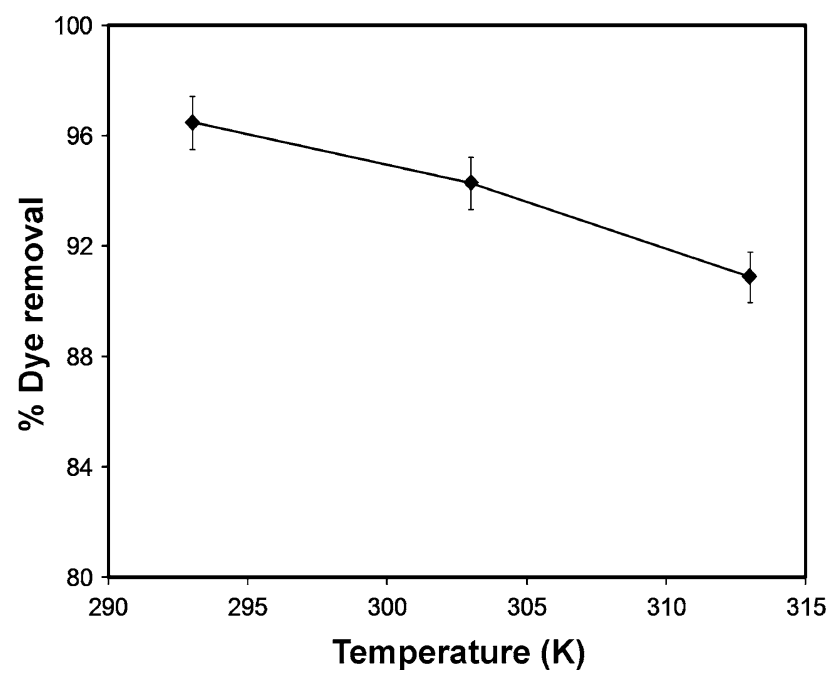

Fig. 4 Effect of temperature on biosorption of CV by PLP (experimental conditions: initial dye concentration $50 \mathrm{mg} \mathrm{L}^{-1}$, biosorbent dosage $2 \mathrm{~g} / 0.1 \mathrm{~L}$, agitation speed $150 \mathrm{rpm}, \mathrm{pH} 8.0$, contact time $3 \mathrm{~h}$ ) listed in Table 1. To quantitatively compare the accuracy of the models, the correlation coefficients $\left(R^{2}\right)$ were also calculated and are also listed in Table 1 . Analysis of the $R^{2}$ values suggests that the Langmuir isotherm model provides best fit to the equilibrium biosorption data at all studied temperatures implying monolayer coverage of $\mathrm{CV}$ molecules onto the biosorbent surface. The maximum monolayer biosorption capacity $\left(q_{\mathrm{m}}\right)$ is $78.22 \mathrm{mg} \mathrm{g}^{-1}$ at $293 \mathrm{~K}$. Table 2 summarizes the comparison of the maximum $\mathrm{CV}$ biosorption capacity of various sorbent materials including PLP. The comparison shows that PLP has higher biosorption capacity of $\mathrm{CV}$ than many of the other reported sorbent materials. Differences in dye uptake capacity are due to the differences in properties of each sorbent material such as structure, functional groups and surface area. The easy availability and cost effectiveness of PLP are some additional advantages, implying that PLP can be a better biosorbent for removal of $\mathrm{CV}$ from aqueous solutions.

The magnitude of the Freundlich constant $n$ gives a measure of favorability of biosorption. Values of $n$ between 1 and 10 represent a favorable biosorption process (Chakraborty et al. 2011). For the present study, the value of $n$ also presents the same trend at all the temperatures indicating favorable nature of biosorption of CV by PLP.

\section{Biosorption kinetics}

The pseudo-first-order and pseudo-second-order kinetic models were used to study the biosorption kinetics of $\mathrm{CV}$ onto PLP (Chowdhury and Saha 2010).

Psuedo - first - order $: \log \left(q_{e}-q_{t}\right)=\log q_{e}-\frac{k_{1}}{2.303} t$

Psuedo - second - order $: \frac{t}{q_{t}}=\frac{1}{k_{2} q_{e}^{2}}+\frac{1}{q_{e}} t$

where $q_{t}$ and $q_{\mathrm{e}}$ are the amount of dye adsorbed at time $t$ and at equilibrium $\left(\mathrm{mg} \mathrm{g}^{-1}\right), k_{1}\left(\mathrm{~min}^{-1}\right)$ is the pseudofirst-order rate constant and $k_{2}\left(\mathrm{~g} \mathrm{mg}^{-1} \mathrm{~min}^{-1}\right)$ is the pseudo-second-order rate constant.

The values of the pseudo-first-order model constants, $k_{1}$ and $q_{\mathrm{e}}$ were calculated from the slope and intercept of the plots of $\log \left(q_{\mathrm{e}}-q_{t}\right)$ versus $t$ while the pseudo-second-order model constants, $k_{2}$ and $q_{\mathrm{e}}$ were calculated from the slope and intercept of the plots of $\mathrm{t} / \mathrm{q}_{\mathrm{t}}$ versus $t$. The calculated model parameters along with the correlation coefficient values $\left(R^{2}\right)$ are listed in Table 1 . As can be seen from Table 1 , the low $R^{2}(<0.90)$ values for the pseudo-firstorder model indicate that this model was not suitable for describing the biosorption kinetics of CV onto PLP. However, the relatively high $R^{2}(>0.99)$ values for the pseudo-second-order model suggest that the ongoing 
Table 1 Isotherm constants and kinetic parameters for biosorption of CV by PLP at different temperatures

\begin{tabular}{|c|c|c|c|}
\hline \multirow[t]{2}{*}{ Model } & \multicolumn{3}{|c|}{ Temperature (K) } \\
\hline & 293 & 303 & 313 \\
\hline \multicolumn{4}{|l|}{ Isotherm models } \\
\hline \multicolumn{4}{|l|}{ Langmuir } \\
\hline$q_{\mathrm{m}}\left(\mathrm{mg} \mathrm{g}^{-1}\right)$ & 78.227 & 75.176 & 72.391 \\
\hline$K_{\mathrm{L}}\left(\mathrm{L} \mathrm{mg}^{-1}\right)$ & 0.861 & 0.722 & 0.654 \\
\hline$R^{2}$ & 0.999 & 0.998 & 0.996 \\
\hline \multicolumn{4}{|l|}{ Freundlich } \\
\hline$K_{\mathrm{F}}\left(\mathrm{mg} \mathrm{g}^{-1}\right)\left(\mathrm{L} \mathrm{mg}^{-1}\right)^{1 / \mathrm{n}}$ & 30.779 & 25.178 & 14.343 \\
\hline$n$ & 4.137 & 3.572 & 2.419 \\
\hline$R^{2}$ & 0.967 & 0.955 & 0.959 \\
\hline \multicolumn{4}{|l|}{ Kinetic models } \\
\hline \multicolumn{4}{|l|}{ Pseudo-first-order } \\
\hline$q_{\mathrm{e}, \mathrm{cal}}\left(\mathrm{mg} \mathrm{g}^{-1}\right)$ & 56.855 & 53.278 & 50.576 \\
\hline$k_{1}\left(\min ^{-1}\right)$ & $8.39 \times 10^{-2}$ & $6.71 \times 10^{-2}$ & $4.19 \times 10^{-2}$ \\
\hline$R^{2}$ & 0.925 & 0.923 & 0.928 \\
\hline \multicolumn{4}{|l|}{ Pseudo-second-order } \\
\hline$q_{\mathrm{e}, \mathrm{cal}}\left(\mathrm{mg} \mathrm{g}^{-1}\right)$ & 74.262 & 71.386 & 68.783 \\
\hline$k_{2}\left(\mathrm{~g} \mathrm{mg}^{-1} \min ^{-1}\right)$ & $6.25 \times 10^{-3}$ & $3.65 \times 10^{-3}$ & $1.32 \times 10^{-3}$ \\
\hline$R^{2}$ & 0.992 & 0.996 & 0.994 \\
\hline
\end{tabular}

Table 2 Comparison of CV biosorption capacity of PLP with other reported low-cost adsorbents

\begin{tabular}{lll}
\hline Sorbent & $\begin{array}{l}q_{\mathrm{max}} \\
\left(\mathrm{mg} \mathrm{g}^{-1}\right)\end{array}$ & Reference \\
\hline Coir pith & 2.56 & Namasivayam et al. 2001 \\
Sugarcane dust & 3.8 & Khattri and Singh 1999 \\
Neem sawdust & 3.8 & Khattri and Singh 2009 \\
Calotropis procera leaf & 4.14 & Ali and Muhammad 2008 \\
Sagaun sawdust & 4.25 & Khattri and Singh 2011 \\
Jalshakti ${ }^{\circledR}$ Polymer & 12.9 & Dhodapkar et al. 2007 \\
Orange peel & 14.3 & Annadurai et al. 2004 \\
Jute fiber carbon & 27.99 & Porkodi and Kumar 2007 \\
Coniferous pinus bark powder & 32.78 & Ahmad 2009 \\
Sawdust & 37.83 & Parab et al. 2009 \\
Rice bran & 42.25 & Wang et al. 2008 \\
Jackfruit leaf powder & 43.39 & Saha et al. 2012 \\
NaOH-modified rice husk & 44.87 & Chakraborty et al. 2011 \\
Japonica & 82.83 & Wang et al. 2008 \\
Wheat bran & 80.37 & Wang et al. 2008 \\
Pineapple leaf powder & 78.22 & This study \\
\hline
\end{tabular}

biosorption process obeys pseudo-second-order kinetics at all studied temperatures. The applicability of the pseudosecond-order kinetic model indicates that the biosorption process of CV onto PLP is chemisorption and the ratedetermining step is probably surface biosorption. The pseudo-second-order rate constant, $k_{2}$ decreases with increase in temperature suggesting exothermic nature of the biosorption process.

Activation parameters

From the pseudo-second-order rate constant $k_{2}$ (Table 1), the activation energy $E_{a}$ for biosorption of CV by PLP was determined using the Arrhenius equation (Chowdhury and Saha 2010):

$\ln k=\ln A-\frac{E_{a}}{R T}$

where $k$ is the rate constant, $A$ is the Arrhenius constant, $E_{a}$ is the activation energy $\left(\mathrm{kJ} \mathrm{mol}^{-1}\right), R$ is the gas constant (8.314 $\mathrm{J} \mathrm{mol}^{-1} \mathrm{~K}^{-1}$ ) and $T$ is the temperature $(\mathrm{K})$. By plotting $\ln k_{2}$ versus $1 / T, E_{a}$ was obtained from the slope of the linear plot and was estimated to be $58.96 \mathrm{~kJ} \mathrm{~mol}^{-1}$. According to literature, biosorption of CV by PLP follows chemisorption (Chowdhury et al. 2011b).

The Eyring equation was used to calculate the standard enthalpy $\left(\Delta H^{\#}\right)$, and entropy of activation $\left(\Delta S^{\#}\right)$ (Chowdhury et al. 2011a):

$\frac{\ln k}{T}=\ln \frac{k_{B}}{h}+\frac{\Delta S^{\#}}{R}-\frac{\Delta H^{\#}}{R T}$

where $k$ is the rate constant, $k_{B}$ is the Boltzman constant $\left(1.3807 \times 10^{-23} \mathrm{~J} \mathrm{~K}^{-1}\right), h$ is the Plank constant $(6.6261 \times$ $\left.10^{-34} \mathrm{Js}\right), R$ is the gas constant $\left(8.314 \mathrm{~J} \mathrm{~mol}^{-1} \mathrm{~K}^{-1}\right)$ and $T$ is the temperature (K). The values of $\Delta H^{\#}$ and $\Delta S^{\#}$ were calculated from the slope and intercept of the plot of 
Table 3 Thermodynamic parameters for biosorption of CV onto PLP

\begin{tabular}{lll}
\hline$\Delta \mathrm{G}^{0}\left(\mathrm{~kJ} \mathrm{~mol}^{-1}\right)$ & $\begin{array}{l}\Delta \mathrm{H}^{0} \\
\left(\mathrm{~kJ} \mathrm{~mol}^{-1}\right)\end{array}$ & $\begin{array}{l}\Delta \mathrm{S}^{0} \\
\left(\mathrm{~J} \mathrm{~mol}^{-1} \mathrm{~K}^{-1}\right)\end{array}$ \\
\hline
\end{tabular}

$293 \mathrm{~K} \quad 303 \mathrm{~K} \quad 313 \mathrm{~K}$

$\begin{array}{lllll}-18.25 & -16.62 & -14.83 & -68.47 & -171.29\end{array}$

$\ln k_{2} / T$ versus $1 / T$ and were found to be $-0.146 \mathrm{~kJ} \mathrm{~mol}^{-1}$ for $\Delta H^{\#}$ and $-198.18 \mathrm{~J} \mathrm{~mol}^{-1} \mathrm{~K}^{-1}$ for $\Delta S^{\#}$. The negative value of $\Delta H^{\#}\left(=-0.146 \mathrm{~kJ} \mathrm{~mol}^{-1}\right)$ indicates exothermic nature of the biosorption process. The negative value of $\Delta S^{\#}$ suggests that biosorption of CV onto PLP is an associative mechanism (Chowdhury et al. 2011a).

The values of $\Delta H^{\#}$ and $\Delta S^{\#}$ were used to compute the free energy of activation $\left(\Delta G^{\#}\right)$ from the relation:

$\Delta G^{\#}=\Delta H^{\#}-T \Delta S^{\#}$

The values of $\Delta G^{\#}$ were found to be $58.21,60.19,62.17$ $\mathrm{kJ} \mathrm{mol}^{-1}$ at $T=293,303$, and $313 \mathrm{~K}$ respectively. The large positive values of $\Delta G^{\#}$ suggest that energy was required in the biosorption reaction to convert reactants into products.

Thermodynamic parameters

The thermodynamic parameters-Gibbs free energy change $\left(\Delta G^{0}\right)$, enthalpy $\left(\Delta H^{0}\right)$ and entropy $\left(\Delta S^{0}\right)$ for the biosorption process were calculated using the following equations for the temperature range 293-313 K (Chowdhury and Saha 2010):

$\Delta G^{0}=-R T \ln K_{C}$

$K_{C}=\frac{C_{a}}{C_{e}}$

$\Delta G^{0}=\Delta H^{0}-T \Delta S^{0}$

where $K_{c}$ is the distribution coefficient for adsorption, $C_{a}$ is the equilibrium dye concentration on the adsorbent ( $\mathrm{mg} \mathrm{L}^{-1}$ ) and $\mathrm{C}_{e}$ is the equilibrium dye concentration in solution $\left(\mathrm{mg} \mathrm{L}^{-1}\right)$.

The calculated Gibbs free energy $\left(\Delta G^{0}\right)$ values at different temperatures for biosorption of CV onto PLP are listed in Table 3. The values of $\Delta H^{0}$ and $\Delta S^{0}$ were determined from the slope and intercept of the plot of $\Delta G^{0}$ versus $T$ and are also listed in Table 3. The negative value of $\Delta G^{0}$ at different temperatures indicates spontaneous nature of the biosorption process. The negative value of $\Delta H^{0}$ indicates that the biosorption reaction is exothermic while the negative value of $\Delta S^{0}$ suggests that the process is enthalpy driven.

\section{Conclusion}

Biosorption potential of PLP to remove $\mathrm{CV}$ from aqueous solutions was investigated. Batch experiments were carried out as function of solution $\mathrm{pH}$, initial dye concentration, biosorbent dose and temperature. Both temperature and $\mathrm{pH}$ were found to have a strong influence on the biosorption process. The biosorption efficiency decreased with increase in initial dye concentration while it increased with increase in biosorbent dose up to a certain level. The Langmuir isotherm showed best fit to the equilibrium biosorption data with maximum monolayer biosorption capacity of $78.22 \mathrm{mg} \mathrm{g}^{-1}$ at $293 \mathrm{~K}$. Kinetic studies showed that the biosorption process followed pseudo-second-order kinetics. The activation energy $\left(E_{a}\right)$ determined using the Arrhenius equation confirmed that biosorption of $\mathrm{CV}$ by PLP involved chemical ion-exchange. Thermodynamic studies showed that the biosorption process was spontaneous and exothermic. Compared to various other sorbents reported in the literature, PLP appears to be a promising biosorbent for practical applicability due to its easy availability and high dye binding capacity. However, to apply this environmentally friendly and efficient biosorbent for the removal of contaminants from real industrial effluents, continuous column studies need to be performed.

Open Access This article is distributed under the terms of the Creative Commons Attribution License which permits any use, distribution, and reproduction in any medium, provided the original author(s) and the source are credited.

\section{References}

Ahmad R (2009) Studies on adsorption of crystal violet dye from aqueous solution onto coniferous pinus bark powder (CPBP). J Hazard Mater 171:767-773

Ali H, Muhammad SK (2008) Biosorption of crystal violet from water on leaf biomass of Calotropis procera. J Environ Sci Technol $1: 143-150$

Annadurai G, Juang R-S, Lee D-J (2004) Use of cellulose-based wastes for adsorption of dyes from aqueous solutions. J Hazard Mater 92:263-274

Chakraborty S, Chowdhury S, Saha PD (2011) Adsorption of crystal violet from aqueous solution onto $\mathrm{NaOH}$-modified rice husk. Carbohydr Polym 86:1533-1541

Chowdhury S, Das P (2011) Mechanistic kinetic and thermodynamic evaluation of adsorption of hazardous malachite green onto conch shell powder. Sep Sci Technol 46:1966-1976

Chowdhury S, Saha P (2010) Sea shell powder as a new adsorbent to remove Basic Green 4 (Malachite Green) from aqueous solutions: equilibrium kinetic and thermodynamic studies. Chem Eng J 164:168-177

Chowdhury S, Mishra R, Kushwaha P, Saha P (2010) Removal of safranin from aqueous solutions by $\mathrm{NaOH}$-treated rice husk: thermodynamics kinetics and isosteric heat of adsorption. AsiaPac J Chem Eng. doi:101002/apj525

Chowdhury S, Mishra R, Saha P, Kushwaha P (2011a) Adsorption thermodynamics kinetics and isosteric heat of adsorption of malachite green onto chemically modified rice husk. Desalination 265:159-168

Chowdhury S, Chakraborty S, Saha P (2011b) Biosorption of Basic Green 4 from aqueous solution by Ananas comosus (pineapple) leaf powder. Coll Surf B 84:520-527 
Demribas A (2009) Agricultural based activated carbons for the removal of dyes from aqueous solutions: a review. J Hazard Mater 167:1-9

Dhodapkar R, Rao NN, Pande SP, Nandy T, Devotta S (2007) Adsorption of cationic dyes on Jalshakti super adsorbent polymer and photocatalytic regeneration of the adsorbent. React Funct Polym 67:540-548

Farooq U, Kozinski JA, Khan MA, Athar M (2010) Biosorption of heavy metal ions using wheat based biosorbents-a review of the recent literature. Bioresour Technol 101:5043-5053

Gupta VK, Suhas (2009) Application of low-cost adsorbents for dye removal-a review. J Environ Manage 90:2313-2342

Khattri SD, Singh MK (1999) Colour removal from dye wastewater using sugarcane dust as an adsorbent. Adsorpt Sci Technol 17:269-282

Khattri SD, Singh MK (2009) Colour removal from synthetic dye wastewater using a biosolid sorbent. Water Air Soil Pollut 120:283-294

Khattri SD, Singh MK (2011) Use of Sagaun sawdust as an adsorbent for the removal of crystal violet dye from simulated wastewater. Environ Prog Sustain Energy. doi:101002/ep10567

Kumar R, Ahmad R (2011) Biosorption of hazardous crystal violet dye from aqueous solution onto treated ginger waste (TGW). Desalination 265:112-118

Namasivayam C, Kumar MD, Selvi K, Begum RA, Vanathi T, Yamuna RT (2001) 'Waste' coir pith—a potential biomass for the treatment of dyeing wastewaters. Biomass Bioenergy 6:477-483

Parab H, Sudersanan M, Shenoy N, Pathare T, Vaze B (2009) Use of agro-industrial wastes for removal of basic dyes from aqueous solutions. Clean Soil Air Water 37:963-969

Porkodi K, Kumar KV (2007) Equilibrium kinetics and mechanism modeling and simulation of basic and acid dyes sorption onto jute fiber carbon: Eosin yellow malachite green and crystal violet single component systems. J Hazard Mater 143:311-327

Rafatullah M, Sulaiman O, Hashim R, Ahmad A (2010) Adsorption of methylene blue on low-cost adsorbents: a review. J Hazard Mater 177:70-80

Saeed A, Sharif M, Iqbal M (2010) Application potential of grapefruit peel as dye sorbent: kinetics equilibrium and mechanism of crystal violet adsorption. J Hazard Mater 179:564-572

Saha P, Chowdhury S, Gupta S, Kumar I (2010) Insight into adsorption equilibrium kinetics and thermodynamics of Malachite Green onto clayey soil of Indian origin. Chem Eng J 165:874-882

Saha PD, Chakraborty S, Chowdhury S (2012) Batch and continuous (fixed-bed column) biosorption of crystal violet by Artocarpus heterophyllus (jackfruit) leaf powder. Coll Surf B 92:262-270

Wang XS, Liu X, Wen L, Zhou Y, Li Z (2008) Comparison of basic dye crystal violet removal from aqueous solution by low-cost biosorbents. Sep Sci Technol 43:3712-3731 